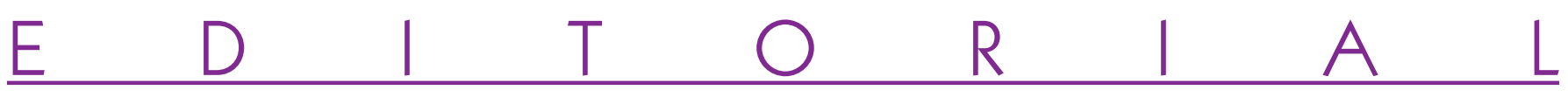

\title{
The orthodontist, the nail, and the hammer
}

When your only tool is a hammer, every problem looks like a nail.

Paul WATZLAWICK

An orthodontist came to hang

A painting on his office wall

A hammer and some nails were all

Our artist thought he needed.

He took great care, his skills were great

At first the nail went in quite straight.

He tried one, two then three blows

All went well but then who knows

The fourth attempt was doomed to fail

The hammer badly bent the nail.

Our hero blew his stach, to no avail

He wildly tapped another nail.

With frenzied blows that went astray

He continued on this frantic way. 
EDITORIAL

Hidden in that traitor plaster Was a stone that spelled disaster

Against this block the nail got twisted

And every blow stoutly resisted.

Trying hard to gild the decor

Our hero blustered more and more

Bending nails by the score

While the painting lay unhung upon the floor.

His youngest patient surely knows

It makes no sense to aim your blows

At nails that fight your hardest shot

Just move their points to another spot.

The moral of this fable is that all clinicians run the risk of falling into the trap of stagnating professionally. They may find it difficult to changer their point of view and contemplate a request for treatment in its widest global sense. In parceling out therapy into limited specialist domains practitioners lose sight of the patient as a whole. Dento-facial orthopedics should deal not just with the patient's faces and occlusions but with their body posture as well. A broadening of outlook is intispensable to our acquiring the information we need to make therapeutic decisions.

Our patients have the right to benefit from efficient treatment in every sense of the word and to be informed about the difference between our convictions and scientific facts. When they use evidence-based treatment

134

Editorial 
clinicians are widening their vision as they grow more prudent and circumspect and less tempted to accept unsubstantiated opinion.

Our patients will benefit enormously if we participate more broadly in inter-disciplinary dialogue. Mo matter what our specialties and specific competences may be (allergy, general dentistry, physical therapy, general medicine, neurology, ophthalmology, otolaryngology, dentofacial orthopedics, orthophony, orthoptics, osteopathy, pediatrics podiatry, psychology, myofunctional therapy, rheumatology, and oral medicine) we are all committed to a holistic response to requests for health care.

Thanks to this necessary and passionate inter-disciplinary cooperation, passing beyond a priori assumptions we can extend our vision to more than occlusion and beyond posture, to observe the human being.

Philippe AMAT 